\title{
B7/CD28 in central tolerance: costimulation promotes maturation of regulatory $T$ cell precursors and prevents their clonal deletion
}

\section{Maria Hinterberger, Gerald Wirnsberger ${ }^{\dagger}$ and Ludger Klein*}

Institute for Immunology, University of Munich, Munich, Germany

\section{Edited by:}

Stephen M. Anderton, University of Edinburgh, UK

Reviewed by: Pennsylvania School of Medicine, USA

Peter M. van Endert, Université Paris Descartes/INSERM, France

Ludger Klein, Institute for Immunology, University of Munich, Goethestrasse 31, 80336 Munich, Germany. muenchen.de

\section{${ }^{+}$Current address:}

Gerald Wirnsberger, Institute of Molecular Biotechnology, Vienna, Austria.
Wayne Hancock, University of

*Correspondence:

e-mail: ludger.klein@med.uni-

According to the "two-step model," the intrathymic generation of $\mathrm{CD} 4^{+}$regulatory $\mathrm{T}\left(\mathrm{T}_{\text {reg }}\right)$ cells segregates into a first, $T$ cell receptor (TCR)-driven phase and a second, cytokinedependent phase. The initial TCR stimulus gives rise to a CD25+Foxp3- developmental intermediate. These precursors subsequently require cytokine signaling to establish the mature $\mathrm{CD}_{2} 5^{+} \mathrm{Foxp}^{+} \mathrm{T}_{\text {reg }}$ cell phenotype. In addition, costimulation via CD28/B7 (CD80/86) axis is important for the generation of $\mathrm{T}_{\text {reg }}$ cell repertoire of normal size. Recent data suggest that $\mathrm{CD} 28$ or $\mathrm{B} 7$ deficient mice lack $\mathrm{CD}_{25} 5^{+}$Foxp3 ${ }^{-} \mathrm{T}_{\text {reg }}$ cell progenitors. However, these data leave open whether costimulation is also required at subsequent stages of $T_{\text {reg }}$ differentiation. Also, the fate of "presumptive" $T_{\text {reg }}$ cells carrying a permissive TCR specificity in the absence of costimulation remains to be established. Here, we have used a previously described TCR transgenic model of agonist-driven $T_{\text {reg }}$ differentiation in order to address these issues. Intrathymic adoptive transfer of $\mathrm{T}_{\text {reg }}$ precursors indicated that costimulation is dispensable once the intermediate $\mathrm{CD} 25^{+} \mathrm{Foxp}^{-}$stage has been reached. Furthermore, lack of costimulation led to the physical loss of presumptive $T_{\text {reg }}$ cells rather than their escape from central tolerance and differentiation into the conventional $\mathrm{CD} 4^{+} \mathrm{T}$ cell lineage. Our findings suggest that CD28 signaling does not primarily operate through enhancing the TCR signal strength in order to pass the threshold intensity required to initiate $T_{\text {reg }}$ cell specification. Instead, costimulation seems to deliver unique and qualitatively distinct signals that coordinately foster the developmental progression of $\mathrm{T}_{\text {reg }}$ precursors and prevent their negative selection.

Keywords: regulatory T cell, thymocyte development, thymus, tolerance, costimulation, thymus epithelium, CD28, B7

\section{INTRODUCTION}

$\mathrm{CD}^{+}$regulatory $\mathrm{T}\left(\mathrm{T}_{\text {reg }}\right)$ cells expressing the transcription factor Foxp3 exert an essential function for the maintenance of selftolerance and immune homeostasis (Sakaguchi, 2004). There is good evidence that a substantial fraction of the $\mathrm{T}_{\text {reg }}$ cell repertoire originates from the thymus; for instance, there is a large degree of sequence-overlap between the T cell receptor (TCR) repertoires of thymic and peripheral Foxp $3^{+}$cells (Hsieh et al., 2006; Pacholczyk et al., 2006; Lio and Hsieh, 2011).

Entry into the $\mathrm{T}_{\text {reg }}$ cell lineage during thymocyte development is believed to depend upon instructive processes ensuing from selfantigen recognition (Wirnsberger et al., 2011). Evidence for this has been obtained in TCR/neo-self-antigen double transgenic systems (Jordan et al., 2001; Apostolou et al., 2002; Kawahata et al., 2002; Aschenbrenner et al., 2007) and also stems from observations that polyclonal thymocytes bearing superantigen-reactive TCRs are substantially enriched in Foxp $3^{+}$cells (Papiernik et al., 1998; Ribot et al., 2006). The exact parameters and modalities of antigen recognition that specify whether an autoreactive MHC II-restricted thymocyte enters the $\mathrm{T}_{\text {reg }}$ lineage or is subject to negative selection remain to be established; however, there is some consensus that interactions of intermediate avidity may favor $\mathrm{T}_{\text {reg }}$ cell differentiation over clonal deletion (Feuerer et al., 2007; Atibalentja et al., 2009; Picca et al., 2009; Hinterberger et al., 2010). [interleukin (IL)-2 in particular, but also IL-7 and -15; Fontenot et al., 2005a; Mayack and Berg, 2006; Yao et al., 2007; Bayer et al., 2008; Vang et al., 2008] as well as costimulation through CD28/B7 interactions are required for efficient intrathymic differentiation of $\mathrm{T}_{\text {reg }}$ cells.

Mice deficient in CD28 or its ligands CD80 and CD86 (B7.1 and B7.2, respectively) display a significant decrease in the number of thymic and peripheral $\mathrm{T}_{\text {reg }}$ cells (Salomon et al., 2000; Tang et al., 2003; Lohr et al., 2004; Tai et al., 2005). Although costimulation has been implicated in IL-2 production (Lindstein et al., 1989; Fraser et al., 1991; Jenkins et al., 1991), the failure of $\mathrm{Cd} 28^{-1-}$ or $\mathrm{Cd} 80 / \mathrm{Cd} 86^{-1-}$ mice to generate a $\mathrm{T}_{\text {reg }}$ cell pool of normal size is not directly linked to cytokine deprivation. Thus, the inefficient entry of $C d 28^{-l-}$ thymocytes into the $\mathrm{T}_{\text {reg }}$ lineage is not "rescued" by the presence of bystander $\mathrm{Cd} 28^{+/+}$cells in mixed bone marrow chimeras, indicating that the paucity of thymic $\mathrm{T}_{\text {reg }}$ cells in costimulation deficient mice primarily reflects a T cell-intrinsic function of the CD28 signaling axis (Tai et al., 2005). Furthermore, co-signals provided by common $\gamma$-chain cytokines 
The "two-step model" of intrathymic $\mathrm{T}_{\text {reg }}$ differentiation suggests a sub-division into an antigen-driven instruction phase and a cytokine-dependent (but largely antigen independent) consolidation phase. Accordingly, CD $25^{+}$Foxp $3^{-}$CD 4 single-positive (SP) cells represent TCR-instructed, $\mathrm{T}_{\text {reg }}$ lineage committed intermediates that require continual cytokine (IL-2, IL-7, or IL-15) signaling, but are largely independent of TCR stimulation, for their differentiation into "mature" CD $25^{+}$Foxp $^{+}{ }^{+} \mathrm{T}_{\text {reg }}$ cells (Burchill et al., 2008; Lio and Hsieh, 2008). Recent data support the idea that CD28 costimulation and common $\gamma$-chain cytokine signaling operate at distinct stages of intrathymic $\mathrm{T}_{\text {reg }}$ differentiation. Specifically, polyclonal CD $25^{+}$Foxp $3^{-}$cells, which are believed to contain $\mathrm{T}_{\text {reg }}$ precursors that arise through TCR-mediated instruction ("step one") are strongly diminished in the thymus of $\mathrm{Cd} 28^{-/-}$mice (Lio et al., 2010; Vang et al., 2010).

The principle requirement for costimulation during intrathymic generation of the $\mathrm{T}_{\text {reg }}$ cell pool has been well documented in polyclonal systems. However, assessing the number of Foxp $3^{+}$cells in a diverse TCR repertoire does not reveal insights into the "alternative" fate of presumptive $\mathrm{T}_{\text {reg }}$ cells in the absence of costimulation. Thus, it is as yet unclear whether the respective TCR specificities are physically lost from the repertoire, i.e., negatively selected, or whether these cells instead escape from central tolerance induction and enter the pool of mainstream CD4 T cells. To address this issue, we have made use of a previously described TCR transgenic model of agonist antigen-driven $\mathrm{T}_{\text {reg }}$ differentiation.

\section{MATERIALS AND METHODS}

\section{MICE}

T cell receptor-hemagglutinin (HA; Kirberg et al., 1994) and AIRE-HA (Aschenbrenner et al., 2007) have been described previously. Foxp3 $3^{\text {gfp }}$ reporter mice (Fontenot et al., 2005b) were kindly provided by A. Rudensky (Memorial Sloan Kettering Insti-

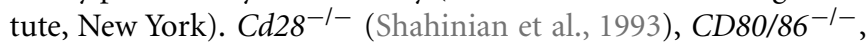
$C D 80^{-/-}$, and $C D 86^{-1-}$ mice (Borriello et al., 1997) were purchased from Jackson Laboratories. BALB/c mice were purchased from Charles River. Mice were maintained in individually ventilated cages. Animal studies were approved by local authorities (Regierung von Oberbayern, 55.2.1.54.2531-7-08).

\section{INTRATHYMIC TRANSFER}

About $5 \times 10^{5} \mathrm{CD} 4 \mathrm{SP}$ thymocytes or $4 \times 10^{5}$ cells of sorted subpopulations from TCR-HA $\times$ AIRE-HA donors (CD45.1) were injected in $3 \mu \mathrm{l}$ PBS into one thymic lobe of CD45.2 recipients of the indicated genotype. The analysis of injected thymi was carried out by depletion of $\mathrm{CD}^{+}$cells, staining for the indicated surface markers and analysis of the entire thymus by flow cytometry.

\section{ANTIBODIES AND FLOW CYTOMETRY}

Phycoerythrin-conjugated annexin-V, phycoerythrin-conjugated monoclonal antibodies (mAbs) to GITR (DTA-1) and PD-1 (J43), cychrome-conjugated mAb to CD8 (53-6.7), phycoerythrin-indotricarbocyanine-conjugated $\mathrm{mAb}$ to $\mathrm{CD} 25$ (PC61), allophycocyanin-conjugated mAb to CD45.1 (A20), allophycocyanin-conjugated $\mathrm{mAb}$ to $\mathrm{BrdU}$ (Cat. No. 5123619L), and allophycocyanin indotricarbocyanine-conjugated $\mathrm{mAb}$ to CD4 (GK1.5) were obtained from Becton Dickinson.
Phycoerythrin-conjugated mAb to Foxp3 (FJK-16s) was from eBiosciences. The mAb to the TCR-HA was purified from hybridoma (6.5) supernatants and conjugated to phycoerythrin or Alexa Fluor 647 in our lab.

\section{BRDU LABELING}

One milligram of BrdU (Becton Dickinson) in $200 \mu \mathrm{l}$ PBS was intraperitoneally injected into recipient mice. $24 \mathrm{~h}$ after injection mice were sacrificed and thymocytes were stained with the indicated surface markers. Subsequently cells were fixed, permeabilized, treated with DNase I, and stained with a mAb specific to BrdU according to the manufacturers protocol (BrdU Flow Kit, Becton Dickinson).

\section{BONE MARROW CHIMERAS}

Bone marrow was depleted of T cells with biotinylated mAbs to CD8 and CD4 followed by depletion with streptavidin MACS beads (Miltenyi Biotec) according to standard procedures. BALB/c recipient mice were irradiated with two split doses of $450 \mathrm{rad}$ and were reconstituted with $8 \times 10^{6}$ bone marrow cells.

\section{PURIFICATION OF CD4 SP CELLS OR T REG PRECURSORS}

CD4 SP cells or subpopulations of CD4 SP cells ( $\mathrm{T}_{\text {reg }}$ precursors) were purified by CD8 depletion, staining for the indicated surface markers, and sorting with a FACSAria cell sorter (Becton Dickinson).

\section{STATISTICAL ANALYSIS}

Statistical significance was assessed by the two-tailed Student's $t$-test with unequal variance.

\section{RESULTS}

\section{LOSS OF PRESUMPTIVE $T_{\text {REG }}$ CELLS IN THE ABSENCE OF COSTIMULATION}

Studies in polyclonal systems have clearly indicated a substantial reduction in the thymic production of $\mathrm{T}_{\text {reg }}$ cells in the absence of costimulation (Bour-Jordan et al., 2011). However, these analyses did not reveal the fate of presumptive $\mathrm{T}_{\text {reg }}$ cells under these circumstances, that is, whether the respective TCR specificities are physically lost from the repertoire or instead enter the naïve pool of CD4 T cells. To address this issue, we used TCR-HA $\times$ AIREHA double transgenic mice. In these animals, expression and presentation of cognate antigen by medullary thymic epithelial cells (mTECs) promotes the negative selection of the majority of influenza HA specific CD4 SP thymocytes, while at the same time a distinct and traceable cohort of HA-specific CD4 SP cells differentiate into $\mathrm{T}_{\text {reg }}$ cells (Aschenbrenner et al., 2007; Hinterberger et al., 2010). T cells expressing the HA-specific TCR (TCR-HA) can conveniently be traced using the anticlonotypic antibody 6.5.

In the absence of cognate antigen, about $30 \%$ of CD4 SP cells express the HA-specific TCR-HA (Figure 1A). Expectedly, in TCR-HA single-transgenic mice, the fraction of TCR-HA ${ }^{+}$ CD4 SP thymocytes was indistinguishable irrespective of whether costimulation was provided or not (data not shown). By contrast, when TCR-HA $\times$ AIRE-HA mice were bred onto a CD28 or CD80/CD86 deficient background, we observed a significantly altered thymic phenotype. Specifically, there was a substantially decreased frequency of TCR-HA ${ }^{+}$cells among CD4 SP 
A
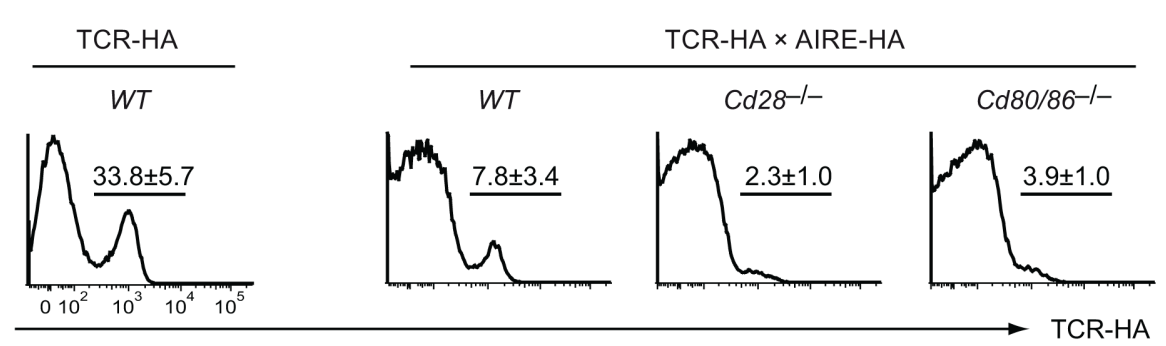

B

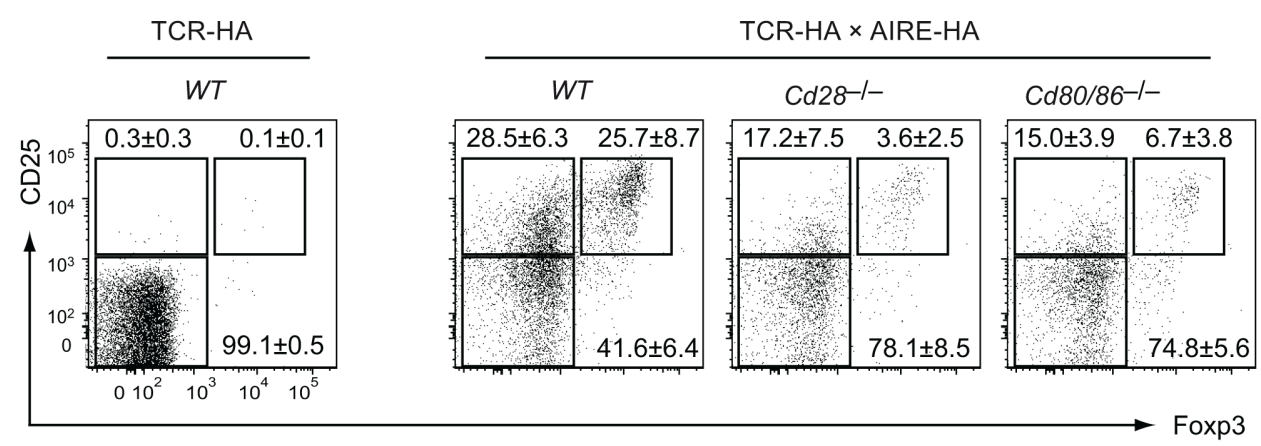

C

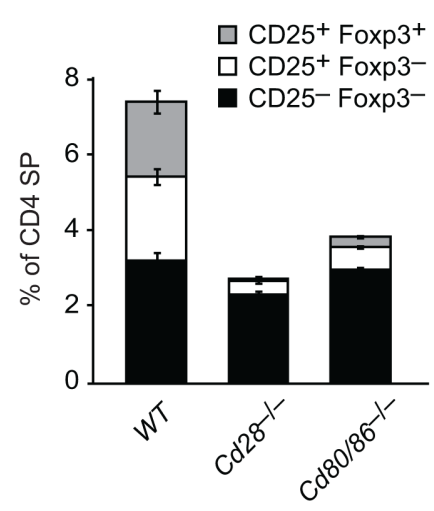

D

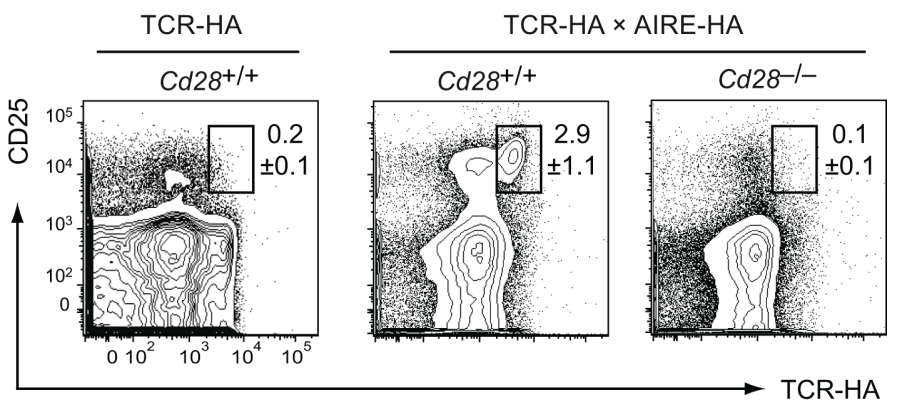

FIGURE 1 | Loss of HA-specific thymic $T_{\text {reg }}$ precursor cells in costimulation deficient mice. Thymocytes from 6-week-old TCR-HA single-transgenic mice and TCR-HA $\times$ AIRE-HA mice on a costimulation sufficient $(=W T), C d 28^{-1-}$ or Cd80/86 $6^{-1-}$ background were stained for CD4, CD8, TCR-HA, CD25, and Foxp3 ( $n=5$ for TCR-HA, $n=36$ for WT TCR-HA $\times$ AIRE-HA, $n=14$ for Cd28-(-) TCR-HA $\times$ AIRE-HA, $n=13$ for Cd80/86 $6^{-1-}$ TCR-HA $\times$ AIRE-HA). (A) Frequency of TCR-HA ${ }^{+}$cells $( \pm \mathrm{SD})$ among CD4 SP cells $\left(P=3 \times 10^{-11}\right.$ for WT vs. $C d 28^{-/-}$and $P=2 \times 10^{-7}$ for WT vs. Cd80/Cd86- $6^{--}$). (B) Expression of CD25 and Foxp3 by gated TCR-HA+ CD4 SP thymocytes. (C) Relative abundance $( \pm \mathrm{SD})$ of TCR-HA positive CD25-Foxp3- ${ }^{-}$and $\mathrm{CD}^{-} 5^{+}{ }^{+}$Foxp3 $^{-} \mathrm{T}_{\text {reg }}$ precursor subpopulations and mature $\mathrm{CD} 25^{+}{ }^{+}$oxp $3^{+} T_{\text {reg }}$ cells among gated CD4 SP thymocytes (CD25-Foxp3- subsets: $P=0.0002$ for WT vs. $\mathrm{Cd} 28^{-/-}$and $P=0.3$ for $W T$ vs. $C d 80 / \mathrm{Cd}^{2} 6^{-1-} ; \mathrm{CD} 25^{+}$Foxp3 subsets: $P=5 \times 10^{-12}$ for $W T$ vs. $C d 28^{-/-}$and $P=1 \times 10^{-10}$ for $W T$ vs. Cd80/Cd86-1-; CD25+Foxp3 $3^{+}$subsets: $P=3 \times 10^{-16}$ for WT vs. Cd28 $8^{-1-}$; and $P=4 \times 10^{-15}$ for $W T$ vs. $\left.C d 80 / C d 86^{-1-}\right)$. The relative and absolute abundance of $\mathrm{CD} 4 \mathrm{SP}$ thymocytes was not significantly different between the various genotypes (data not shown). (D) Expression of CD25 and TCR-HA by gated $\mathrm{CD} 4^{+} \mathrm{T}$ cells from peripheral lymph nodes of the indicated genotype. thymocytes when compared to costimulation competent TCR$\mathrm{HA} \times$ AIRE-HA controls (Figure 1A). These somewhat surprising initial findings indicated that lack of costimulation augmented the antigen-driven loss of HA-specific CD4 SP cells.

Among TCR-HA ${ }^{+}$CD4 SP thymocytes of costimulation sufficient TCR-HA $\times$ AIRE-HA mice, we found that $\mathrm{CD}_{25}{ }^{-}$Foxp $^{-}{ }^{-}, \mathrm{CD}_{2} 5^{+}$Foxp3 $^{-}$, and $\mathrm{CD} 25^{+}$Foxp $^{+}$cells are represented at roughly equal proportions (Figure 1B, and Wirnsberger et al., 2009). Consistent with the "twostep" model of $\mathrm{T}_{\text {reg }}$ cell development (Lio and Hsieh, 2008), we have shown previously that these subsets represent consecutive stages of agonist induced $\mathrm{T}_{\text {reg }}$ cell development $\left(\mathrm{CD} 25^{-}\right.$Foxp $^{-} \rightarrow \mathrm{CD}^{-} 5^{+}$Foxp $^{-} \rightarrow \mathrm{CD}^{-} 5^{+}$Foxp $^{+}$; Wirnsberger et al., 2009). In the absence of CD28 or CD80/CD86 costimulation, the percentage of "mature" $\mathrm{CD} 25^{+} \mathrm{Foxp}^{+}$ $\mathrm{T}_{\text {reg }}$ cells among TCR-HA ${ }^{+}$CD4 SP thymocytes and their 
immediate $\mathrm{CD} 25^{+} \mathrm{Foxp}^{-}$precursors was considerably decreased (Figures 1B,C). Instead, the majority of residual TCR-HA ${ }^{+}$ CD4 SP cells were CD25-Foxp3 ${ }^{-}$, suggesting a developmental bottleneck at the transition from a CD25- Foxp $3^{-}$to a CD25 ${ }^{+}$Foxp $3^{-}$phenotype, i.e., at the TCR-driven "step one" of $\mathrm{T}_{\text {reg }}$ cell differentiation.

The CD25 ${ }^{-}$Foxp3 $3^{-}$surface phenotype of the majority of TCR$\mathrm{HA}^{+} \mathrm{CD} 4 \mathrm{SP}$ cells in costimulation deficient mice might have indicated that these cells are naive cells that have not received a " $\mathrm{T}_{\text {reg }}$ instructing" TCR signal of appropriate strength. Potentially, such cells might escape from central tolerance induction and seed peripheral lymphoid organs. If this were the case, one might expect to find TCR- $\mathrm{HA}^{+}$non- $\mathrm{T}_{\text {reg }} \mathrm{CD} 4^{+} \mathrm{T}$ cells in the periphery of costimulation deficient TCR-HA $\times$ AIRE-HA mice. However, inspection of peripheral CD4 $\mathrm{T}$ cell compartments revealed the complete absence of TCR-HA ${ }^{+}$cells in costimulation deficient mice (Figure 1D). Specifically, not only was the distinct population of TCR-HA ${ }^{+} \mathrm{CD} 25^{+} \mathrm{T}_{\text {reg }}$ cells that is seen in costimulation sufficient mice absent, but there was also no discernible emergence of TCR-HA ${ }^{+} \mathrm{CD}^{-} 5^{-}$cells in peripheral lymphoid organs (Figure 1D).

In order to address in how far either CD80 or CD86 provided the essential signals for $\mathrm{T}_{\text {reg }}$ cell differentiation, we bred the TCR-HA $\times$ AIRE-HA system onto the respective single knockout background. This revealed a degree of redundancy of the two B7 family members in that both $C d 80^{-1-}$ and $C d 86^{-1-}$ mice only showed a relatively mild reduction of $\mathrm{CD} 25^{+}$Foxp $3^{-}$precursors and their "mature" $\mathrm{CD} 25^{+}$Foxp $3^{+}$progeny among TCR-HA ${ }^{+}$ CD4 SP thymocytes (Figures 2A,B).

In sum, these observations are consistent with a role of costimulation in the TCR-driven development of early intermediates of thymic $\mathrm{T}_{\text {reg }}$ development. A similar conclusion has recently been drawn from the absence of $\mathrm{CD}_{2} 5^{+} \mathrm{GITR}^{+} \mathrm{CD} 122^{+}$cells among polyclonal CD4 SP cells of $C d 28^{-1-}$ mice (Lio et al.,
2010; Vang et al., 2010). Importantly, our data suggest that lack of costimulation, rather than allowing these presumptive $\mathrm{T}_{\text {reg }}$ cells to escape from clonal deviation and to enter the naïve repertoire, leads to physical loss of the respective specificities. In other words, under conditions that are otherwise permissive for $\mathrm{T}_{\text {reg }}$ cell differentiation (i.e., appropriate strength of TCR stimulus), lack of costimulation results in the conversion of $\mathrm{T}_{\text {reg }}$ differentiation into negative selection.

\section{THE FUNCTION OF COSTIMULATION EXTENDS BEYOND IL-2 SIGNALING AND IS CELL-INTRINSIC}

CD28 costimulation has been implicated in IL-2 production (Lindstein et al., 1989; Fraser et al., 1991; Jenkins et al., 1991). Hence, its abrogation may impinge on $\mathrm{T}_{\text {reg }}$ cell differentiation through lack of IL-2 mediated cell extrinsic survival and/or differentiation signals that orchestrate the cytokine-dependent "second" phase of $\mathrm{T}_{\text {reg }}$ cell differentiation (Burchill et al., 2008; Lio and Hsieh, 2008; Wirnsberger et al., 2009). However, upon breeding onto an $I 2^{-1-}$ background, thymi of TCR-HA $\times$ AIRE-HA mice - in contrast to what was observed in $\mathrm{Cd} 28^{-1-}$ or $\mathrm{Cd} 80 / 86^{-1-}$ mice - did not show a reduction of TCR-HA ${ }^{+}$CD4 SP cells and of mature $\mathrm{CD} 25^{+}$cells within this population (Figure 3 ). This is consistent with earlier observations that IL-2 acts on thymic $\mathrm{T}_{\text {reg }}$ cell differentiation in an at least partly redundant manner with other common $\gamma$-chain cytokines such IL-7 or IL-15 (D'Cruz and Klein, 2005; Fontenot et al., 2005a; Vang et al., 2008) and indicates that the apparent developmental blockade and loss of TCR-HA ${ }^{+}$ $\mathrm{T}_{\text {reg }}$ cells in CD28 or CD80/86 deficient TCR-HA $\times$ AIRE-HA mice cannot be explained by an eventual requirement of CD28/B7 costimulation solely for IL-2 production.

In order to test whether the requirement for costimulation was cell-intrinsic, we generated mixed bone marrow chimeras. Irradiated AIRE-HA mice or wild-type controls were reconstituted with a $1 / 1$ mixture of TCR-HA transgenic $C d 28^{+/+}$and $C d 28^{-/-}$
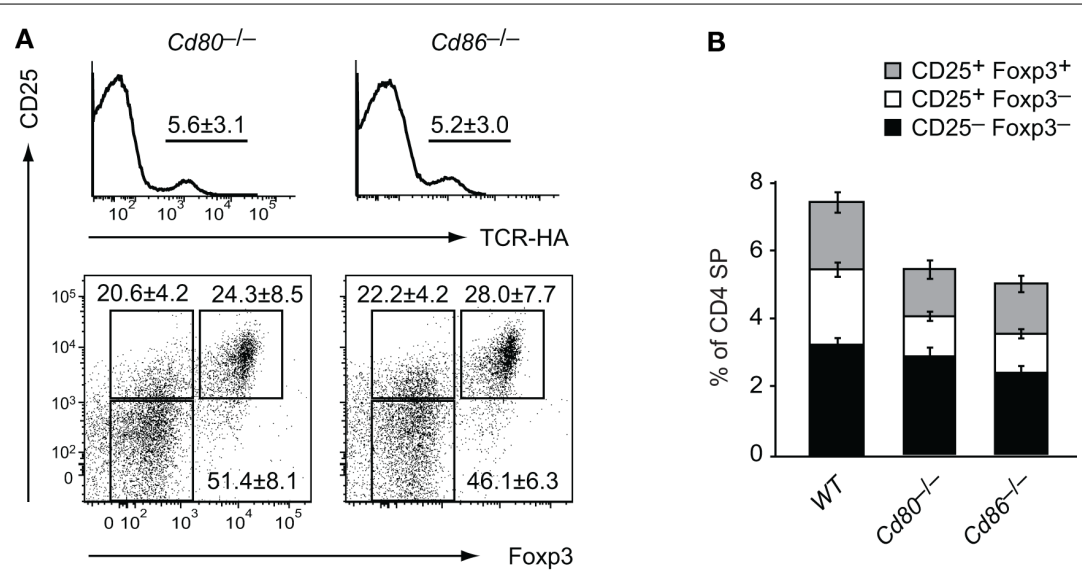

FIGURE 2 | Partially redundant role of CD80 and CD86 for intrathymic $\mathrm{T}_{\text {reg }}$ development. Thymocytes from 6-week-old TCR-HA $\times$ AIRE-HA mice on a Cd80-1- $(n=14)$ or $C d 86^{-1-}(n=20)$ background were stained for CD4, CD8, TCR-HA, CD25, and Foxp3. (A) Frequency of TCR-HA+ cells $( \pm \mathrm{SD})$ among CD4 SP cells $\left(P=0.09\right.$ for $W T$ vs. $C d 80^{-1-}$ and $P=0.03$ for $W T$ vs. $C d 86^{-1-}$; upper panel). The lower panel depicts the expression of CD25 and Foxp3 by gated TCR-HA+ CD4 SP thymocytes.
(B) Relative abundance ( \pm SD) of TCR-HA positive CD25-Foxp3- and CD25+Foxp3 ${ }^{-} \mathrm{T}_{\text {reg }}$ precursor subpopulations and mature CD25+Foxp3 ${ }^{+} \mathrm{T}_{\text {reg }}$ cells among gated CD4 SP thymocytes (CD25-Foxp3- subsets: $P=0.8$ for $W T$ vs. $C d 80^{-1-}$ and $P=0.4$ for WT vs. $C d 86^{-1-} ; C^{2} 25^{+}$Foxp3 $3^{-}$subsets: $P=0.003$ for $W T$ vs. $C d 80^{-1-}$ and $P=0.0002$ for $W T$ vs. $C d 86^{-1-}$; CD25 ${ }^{+}$Foxp3 $3^{+}$subsets: $P=0.08$ for $W T$ vs. $C d 80^{-1-}$ and $P=0.06$ for $W T$ vs. Cd80/Cd86 $\left.{ }^{-/-}\right)$. 


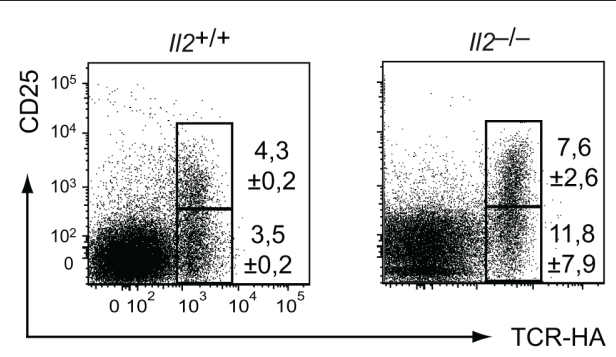

FIGURE 3 | Efficient intrathymic $T_{\text {reg }}$ differentiation in IL-2 deficient TCR-HA $\times$ AIRE-HA mice. Thymocytes from 3-week-old TCR-HA $\times$ AIRE-HA mice on an $1 / 2^{+/+}(n=3)$ or $1 / 2^{-1-}(n=3)$ background were stained for CD4, CD8, TCR-HA, CD25, and Foxp3. Numbers indicate the average frequency $( \pm S D)$ of cells within gates.

bone marrow cells (Figure 3). As expected, in the absence of cognate antigen, $C d 28^{+l+}$, and $C d 28^{-l-}$ cells equally contributed to all thymocyte subsets (not shown). In the presence of cognate antigen, TCR-HA ${ }^{+}$cells represented about $6 \%$ of $C d 28^{+/+}$cells among CD4 SP thymocytes and segregated into CD25 ${ }^{-}$Foxp $^{-}$, CD $25^{+}$Foxp $^{-}$, and CD $25^{+}$Foxp $3^{+}$subsets similar to what was observed in TCR-HA $\times$ AIRE-HA mice (Figure 4B; compare Figures 1A,B). By contrast, TCR-HA ${ }^{+}$cells made up for only about $3 \%$ of $C d 28^{-1-}$ cells among CD4 SP cells, and the majority of these cells had a CD25- Foxp3- $3^{-}$phenotype (Figure 4B). Overall, the contribution of $\mathrm{Cd} 28^{+/+}$and $\mathrm{Cd} 28^{-/-}$cells to $\mathrm{CD} 25^{-}$Foxp3 ${ }^{-}$ TCR-HA ${ }^{+}$thymocytes reflected the $1 / 1$ input ratio, whereas $C d 28^{-1-}$ cells were strongly underrepresented among the subsequent $\mathrm{CD} 25^{+}$Foxp $3^{-}$"intermediate" population and were barely detectable within the "mature" CD $25^{+}$Foxp $3^{+}$subset (Figure 4C).

Together, these findings clearly indicated that costimulation sufficient bystander cells do not rescue the progression of CD28 deficient cells toward a mature $\mathrm{T}_{\text {reg }}$ cell phenotype, for instance through provision of IL-2 or other factors in trans. Instead, there is a cell-intrinsic requirement for CD28 signaling at the earliest stages of $\mathrm{T}_{\text {reg }}$ cell differentiation that is unrelated to the presumed role of IL-2 at a subsequent stage of this process.

\section{CD28 DEFICIENT HA-SPECIFIC CD25-FOXP3- CELLS ARE NOT NAIVE}

Our results so far revealed that in the presence of cognate antigen, HA-specific CD4 SP cells with a CD $25^{-}$Foxp $3^{-}$phenotype could be found in similar proportions irrespective of whether or not CD28/B7 costimulation was available, whereas CD25 ${ }^{+}$Foxp $3^{-}$and $\mathrm{CD} 25^{+}$Foxp $3^{+}$cells were strongly reduced in the absence of costimulation. This suggested a developmental blockade at the transition to a CD25 $5^{+}$Foxp $3^{-}$phenotype, i.e., at "step one" of $\mathrm{T}_{\text {reg }}$ cell differentiation. Alternatively, it was possible that $\mathrm{CD}_{25}{ }^{-}$Foxp $3^{-}$ CD4 SP cells only in a costimulation sufficient environment represented a true $\mathrm{T}_{\text {reg }}$ intermediate downstream of the initiating TCR stimulus, whereas in the absence of costimulation, CD25 ${ }^{-}$Foxp $3^{-}$ CD4 SP cells may instead actually be naïve cells.

In order to distinguish these two possibilities, we performed a more detailed surface marker analysis of $C d 28^{+/+}$and $C d 28^{-1-}$ CD25 ${ }^{-}$Foxp3 $3^{-}$CD4 SP thymocytes in the mixed bone marrow chimeras depicted in Figure $\mathbf{4 A}$ and compared their phenotype to bona fide "naïve" CD25-Foxp3- CD4 SP thymocytes from TCR-HA single-transgenic mice (Figure 4D). Both $C d 28^{+/+}$and
Cd28 $8^{-1-}$ CD25 $5^{-}$Foxp3 $3^{-}$CD4 SP thymocytes displayed a similar up-regulation of the surface molecules PD-1 and GITR, whereas truly naïve CD4 SP cells were PD-1 negative and GITR ${ }^{\text {low }}$. In further support that $C d 28^{+/+}$and $C d 28^{-/-} \mathrm{CD} 25^{-}$Foxp3 ${ }^{-}$CD4 SP thymocytes had received a similar TCR stimulus, expression of the TCR was similarly down-regulated on either population, presumably as a result of cognate antigen encounter (Figure 4D).

In sum, these findings provided further evidence that in the absence of costimulation, HA-specific cells do not escape as naïve T cells. Instead, our observations support the idea that irrespective of whether or not costimulation is provided, TCR-HA ${ }^{+}$progenitors receive a TCR signal that is sufficient to mediate the acquisition of an "early" $\mathrm{T}_{\text {reg }}$ progenitor phenotype. However, in the absence of CD28 signals, these cells only very inefficiently progress toward the subsequent $\mathrm{CD} 25^{+}$Foxp $3^{-}$stage and the mature $\mathrm{CD} 25^{+}$Foxp $3^{+}$ $\mathrm{T}_{\text {reg }}$ phenotype.

\section{COSTIMULATION DOES NOT ACT VIA PROLIFERATIVE EXPANSION OF $T_{\text {REG }}$ CELL PRECURSORS}

So far, we have considered that in the absence of costimulation, the earliest phase of $\mathrm{T}_{\text {reg }}$ differentiation represents a developmental dead end. An alternative explanation for the paucity of CD $25^{+}$Foxp $3^{-}$cells and their $\mathrm{CD}^{2} 5^{+}$Foxp $^{+}$progeny in CD28 or CD80/86 deficient mice would be that costimulation would orchestrate the entry of $\mathrm{T}_{\text {reg }}$ cell precursors into cell cycling, thereby mediating the proliferative expansion of intermediate $\mathrm{T}_{\text {reg }}$ precursors rather than their actual developmental progression. Of note, despite a certain consensus that cycling of "mature" Foxp $3^{+}$thymocytes is barely detectable, it is as yet unclear whether $\mathrm{T}_{\text {reg }}$ cell differentiation involves an early expansion phase prior to Foxp3 expression. This is particularly relevant for the earliest $\mathrm{CD} 25^{-}$Foxp $3^{-}$progenitor stage, because in a polyclonal repertoire these early $\mathrm{T}_{\text {reg }}$ precursors are essentially impossible to distinguish from the bulk of "naïve" non- $\mathrm{T}_{\text {reg }}$ cell precursors.

In order to address this question, we performed BrdU labeling experiments. $24 \mathrm{~h}$ after a single injection of BrdU into $\mathrm{Cd} 28^{+/+}$ TCR-HA $\times$ AIRE-HA mice, a substantial fraction of TCR-HA ${ }^{+}$ CD25 ${ }^{-}$Foxp $3^{-}$cells and to a lesser extent also of CD25 ${ }^{+}$Foxp $3^{-}$ "intermediate" precursors had incorporated BrdU, whereas $\mathrm{BrdU}^{+}$ cells were very rare among mature Foxp $3^{+}$cells (Figure 5A). In the absence of costimulation (in $C d 28^{-1-}$ TCR-HA $\times$ AIREHA mice), TCR-HA ${ }^{+} \mathrm{CD}_{2} 5^{-}$Foxp $3^{-}$cells incorporated similar amounts of BrdU when compared to their counterparts in $\mathrm{Cd} 2 \mathrm{8}^{+/+}$mice, indicating that entry into the cell cycle of this early $\mathrm{T}_{\text {reg }}$ cell precursor-population is independent of CD28/B7mediated costimulatory signals (Figure 5A). Somewhat surprisingly, the incorporation of BrdU by $\mathrm{CD} 25^{+}$Foxp $3^{-}$cells and also by "mature" CD $25^{+}$Foxp $3^{+}$thymocytes was even increased rather than diminished in the absence of CD28 co-signals (Figures 5A,B).

In order to address whether these observations similarly applied to non-transgenic polyclonal TCR specificities, we also compared the BrdU incorporation by TCR-HA ${ }^{-}$CD4 SP thymocytes of $C d 28^{+/+}$and $C d 28^{-/-}$TCR-HA $\times$AIRE-HA mice. These cells express endogenously rearranged TCRs, and their eventual entry into the $\mathrm{T}_{\text {reg }}$ lineage reflects polyclonal $\mathrm{T}_{\text {reg }}$ development. Indeed, a clear tendency toward more proliferation in the absence of costimulation was also observed for $\mathrm{CD} 25^{+}$Foxp $3^{-}$and 


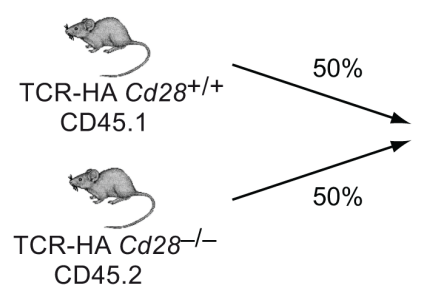

C
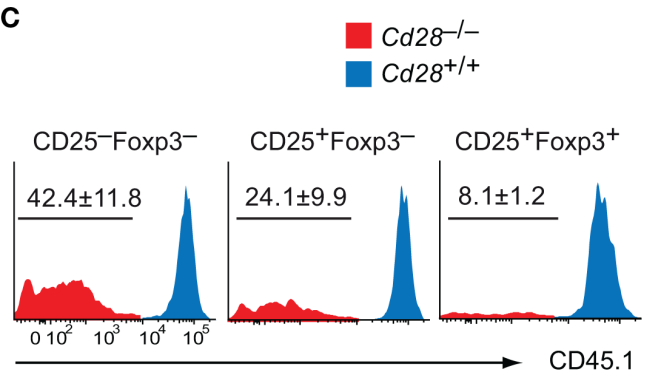

D

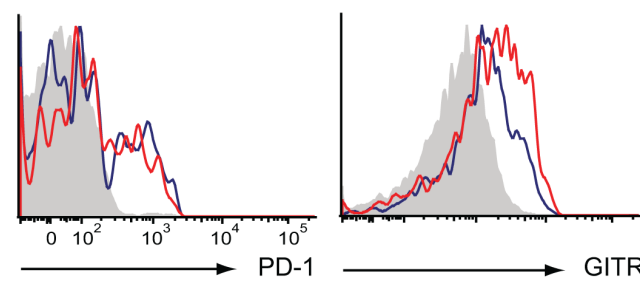

FIGURE 4 | Cell-intrinsic function of CD28 in intrathymic $T_{\text {reg }}$ development. (A) Experimental strategy to generate mixed bone marrow (bm) chimeras. Specifically, $4 \times 10^{6} \mathrm{Cd} 28^{+/+}$TCR-HA bm cells (CD45.1) and $4 \times 10^{6} \mathrm{Cd}_{28^{-1}} \mathrm{TCR}-\mathrm{HA}$ bm cells (CD45.2) were i.v. injected into irradiated AIRE-HA recipients $(n=9)$. Six weeks after bm-reconstitution, CD8 depleted thymocytes were stained for CD4, TCR-HA, CD25, CD45.1, CD45.2, and Foxp3. (B) Frequency of TCR-HA+ cells $( \pm \mathrm{SD})$ among Cd28 $8^{+/+}\left(\mathrm{CD} 45.1^{+}\right)$and Cd28 ${ }^{-{ }^{-}}\left(\mathrm{CD} 45.1^{-}\right) \mathrm{CD} 4 \mathrm{SP}$ cells (upper panel; $\left.P=0.04\right)$. The lower panel depicts the expression of CD25 and Foxp3 by gated $\mathrm{Cd} 28^{+/+}\left(\mathrm{CD} 45.1^{+}\right)$or $\mathrm{Cd}_{28^{-/-}}\left(\mathrm{CD} 45.1^{-}\right) \mathrm{TCR}-\mathrm{HA}{ }^{+} \mathrm{CD} 4 \mathrm{SP}$ thymocytes. (C) Relative abundance of
B

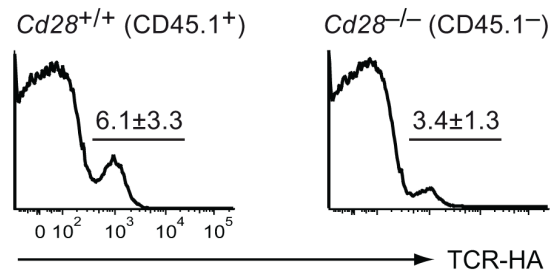

gated TCR-HA
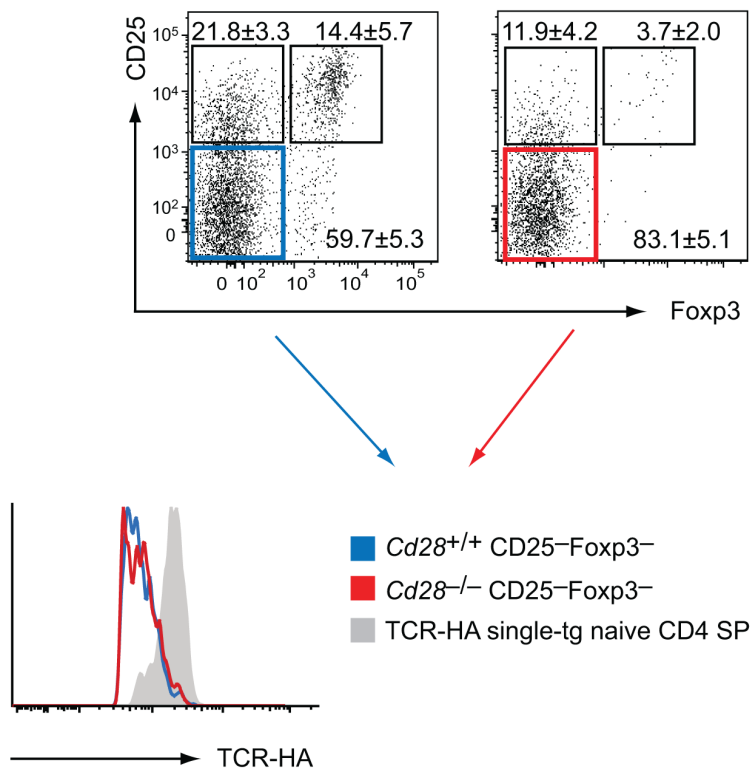

$\mathrm{Cd} 28^{+/+}$CD25-Foxp3-

Cd28-l- CD25-Foxp3-

TCR-HA single-tg naive CD4 SP "mature" CD25 ${ }^{+} \mathrm{Foxp}^{+}$cells among TCR-HA ${ }^{-} \mathrm{CD} 4 \mathrm{SP}$ thymocytes, emphasizing that our observations for TCR transgenic $\mathrm{T}_{\text {reg }}$ cells and their precursors faithfully recapitulated the behavior of polyclonal T cells (Figure 5B).

Taken together, our findings suggest that the early specification into the $\mathrm{T}_{\text {reg }}$ cell lineage indeed coincides with entry of "pre-Foxp3" $\mathrm{T}_{\text {reg }}$ precursors into cell cycling. However, our data strongly argue against a requirement for CD28/B7 costimulation for proliferative expansion of a minute "TCR-primed" precursor-population.

\section{THE TCR-DRIVEN INSTRUCTIVE BUT NOT THE CYTOKINE-DEPENDENT CONSOLIDATION PHASE OF TREG DIFFERENTIATION REQUIRES COSTIMULATION}

A precise assessment of where and when costimulation is required during intrathymic $\mathrm{T}_{\text {reg }}$ cell development is difficult to achieve
Cd28 $8^{+/+}\left(C D 45.1^{+}\right.$; depicted in blue) vs. Cd28 $8^{-/-}$(CD45.1 $1^{-}$; depicted in red) cells among $\mathrm{CD}_{2} 5^{-} \mathrm{Foxp}^{-}$and $\mathrm{CD}^{-} 5^{+} \mathrm{Foxp}^{-} \mathrm{T}_{\text {reg }}$ precursor subpopulations or mature $\mathrm{CD} 25^{+} \mathrm{Foxp}^{+} \mathrm{T}_{\text {reg }}$ cells, gated on all TCR-HA+ CD4 SP thymocytes. Numbers indicate the average frequency $( \pm S D)$ of cells within gates.

(D) Sub-fractions of cells were also stained for PD-1 or GITR. The expression of PD-1 or GITR as well as TCR-HA on gated CD25-Foxp3-TCR-HA ${ }^{-}$CD4 SP thymocytes of $\mathrm{Cd} 28^{+/+}$(blue histogram) or $\mathrm{Cd} 28^{-1-}$ (red histogram) origin was assessed. The gray histogram indicates the expression of the respective markers on "naïve" CD25-Foxp3-TCR-HA+ CD4 SP thymocytes from TCR-HA single-transgenic animals. when studying steady state thymocyte differentiation. For instance, it is possible that the requirement for costimulation even precedes the TCR stimulus, whereby costimulation may somehow prime cells for a subsequent instructive signal. Similarly, an early bottleneck in $\mathrm{T}_{\text {reg }}$ differentiation may mask a continual requirement for costimulation also at a subsequent stage of $\mathrm{T}_{\text {reg }}$ differentiation.

Our observations so far did not reveal whether the costimulatory interactions that support $\mathrm{T}_{\text {reg }}$ differentiation occur before the CD4 SP T cell stage, for instance concomitant to positive selection. We have shown previously that $\mathrm{T}_{\text {reg }}$ differentiation in the TCR-HA $\times$ AIRE-HA thymus can be dissociated from positive selection and CD4 lineage commitment. Specifically, injection of CD4 SP cells from TCR-HA Rag2 ${ }^{-/-}$mice, i.e., truly naïve, monoclonal cells that did not contain any pre-existing Foxp $3^{+}$cells, into AIRE-HA thymi resulted in a substantial fraction of cells entering 


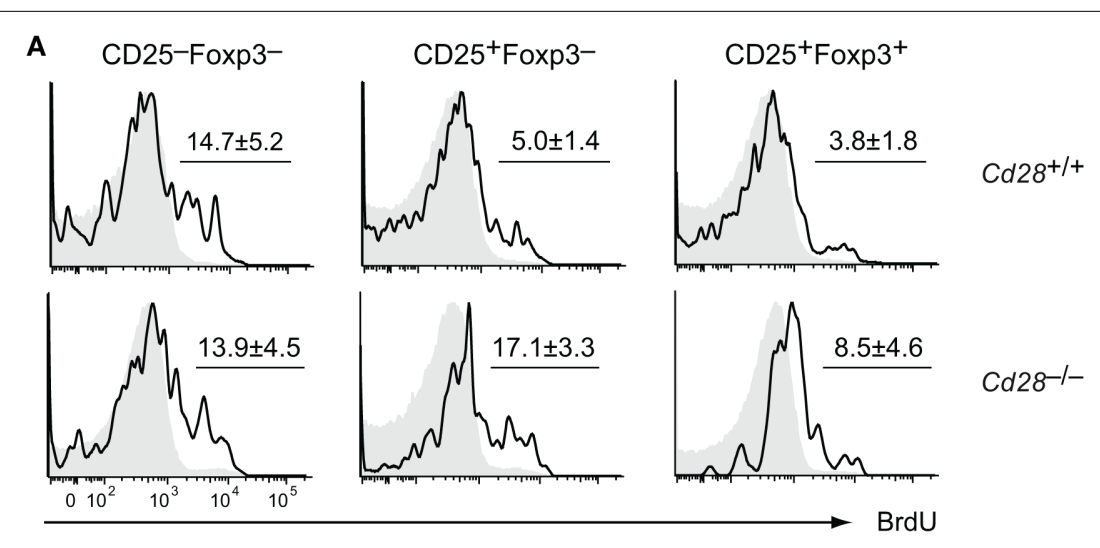

B TCR-HA+ CD4 SP cells

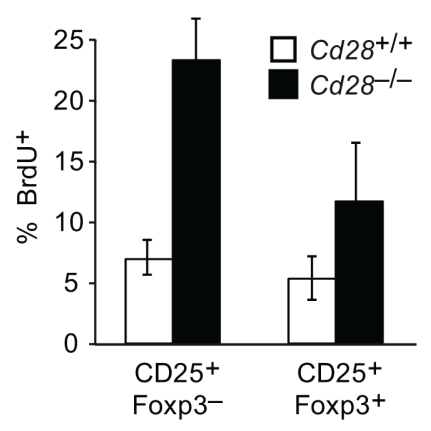

FIGURE 5 | Proliferation of TCR-HA ${ }^{+} \mathbf{T}_{\text {reg }}$ precursors is not reduced in the absence of CD28 and recapitulates the behavior of thymocytes expressing diverse TCRs. $24 \mathrm{~h}$ after a single injection of $\mathrm{BrdU}$, thymocytes from TCR-HA $\times$ AIRE-HA mice on a Cd28 $8^{++}(n=4)$ or $C d 28^{-1-}(n=7)$ background were stained for CD4, CD8, TCR-HA, CD25, Foxp3, and BrdU incorporation. (A) Extent of BrdU incorporation (black open histogram) by gated TCR-HA+ $\mathrm{CD}^{+} \mathrm{SPT}_{\text {reg }}$ precursors (CD25- $\mathrm{Foxp3}^{-}$or $\left.\mathrm{CD}^{2} 5^{+} \mathrm{Foxp}^{-}\right)$or mature TCR-HA+ $\mathrm{CD} 4 \mathrm{SPT}_{\text {reg }}$ cells (CD25 ${ }^{+} \mathrm{Foxp}^{+}$) in $\mathrm{Cd} 28^{+/+}$(upper panels)
TCR-HA- CD4 SP cells

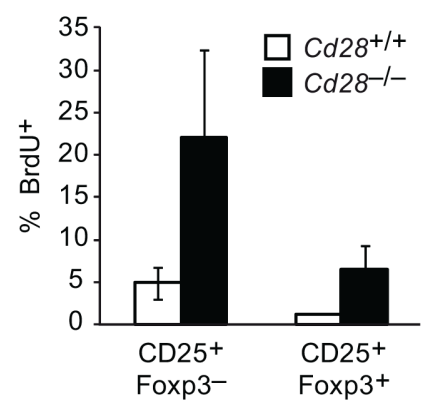

or $\mathrm{Cd}_{28^{-/-}}$(lower panels) mice. Isotype control staining of the respective samples are shown as histogram overlay (gray filled; $P=0.8$ for $\mathrm{CD}^{2} 5^{-}$Foxp3 subsets; $P=2 \times 10^{-4}$ for $\mathrm{CD}_{2} 5^{+} \mathrm{Foxp}^{-}$subsets; $P=0.04$ for $\mathrm{CD}_{25} 5^{+} \mathrm{Foxp}^{+}$subsets) (B) Comparison of $\mathrm{BrdU}$ incorporation by $\mathrm{Cd} 28^{+/+}$(white bars) or $\mathrm{Cd} 28^{-/-}$(black bars) CD25+Foxp3 ${ }^{-}$or $\mathrm{CD}_{2} 5^{+} \mathrm{Foxp}^{+} \mathrm{CD} 4 \mathrm{SP}$ thymocytes that either express the transgenic TCR-HA (left panel) or express endogenously rearranged TCRs (TCR-HAright panel). the CD $25^{+}$Foxp $3^{+} \mathrm{T}_{\text {reg }}$ cell lineage (Wirnsberger et al., 2009; see also Figure 6). These finding indicated that self-antigen-driven intrathymic $\mathrm{T}_{\text {reg }}$ differentiation can be initiated in the absence of "nominal" antigen encounter prior to the CD4 SP stage.

In order to dissociate positive selection in the absence or presence of CD28/B7 costimulatory interactions from cognate antigen encounter at the CD4 SP stage in the absence or presence of costimulation, we intrathymically (i.t.) injected CD28 deficient Rag2-l- TCR-HA SP thymocytes into AIRE-HA recipients. In a "reciprocal" setting, we injected $\operatorname{Rag} 2^{-/-}$TCR-HA SP cells from costimulation sufficient animals into $C d 80 / 86^{-/-}$recipients (Figure 6). Both sets of experiments yielded essentially identical outcomes, namely an almost complete absence of $\mathrm{T}_{\text {reg }}$ differentiation, suggesting that costimulation is necessary concomitant to or immediately subsequent to the instructing TCR stimulus (Figure 6).

Our data so far revealed an essential requirement for costimulation simultaneous to or in close temporal proximity to the instructing TCR stimulus. When analyzing steady state $\mathrm{T}_{\text {reg }}$ cell development in the absence of costimulation, the early developmental arrest at the $\mathrm{CD} 25^{-}$Foxp $3^{-}$stage precludes the analysis of an eventually continual requirement for CD28/B7 interactions at subsequent stages of $\mathrm{T}_{\text {reg }}$ differentiation. In order to address this issue, we isolated $\mathrm{CD}^{2} 5^{-}$Foxp ${ }^{-} \mathrm{GITR}^{+}$cells (i.e., the earliest distinct subset of TCR-triggered $\mathrm{T}_{\text {reg }}$ cell precursors) and cells at the subsequent $\mathrm{CD} 25^{+}$Foxp $3^{-}$intermediate stage (i.e., cells that require common $\gamma$-chain cytokines - but not TCR stimulation - to mature into CD $25^{+}$Foxp3 ${ }^{+}$ cells) from costimulation sufficient TCR-HA $\times$ AIRE-HA mice and injected them into $C d 80 / 86^{-1-}$ recipient thymi (Figure $7 \mathrm{~A}$ ). This revealed that $\mathrm{CD} 25^{-} \mathrm{Foxp}^{-} \mathrm{GITR}^{+}$input cells were strongly dependent upon persistent costimulation to progress toward a mature $\mathrm{T}_{\text {reg }}$ phenotype, whereas $\mathrm{CD} 25^{+}$Foxp $3^{-}$cells gave rise to mature $T_{\text {reg }}$ cells irrespective of whether or not continual costimulation was provided in the host microenvironment (although $\mathrm{T}_{\text {reg }}$ occurred perhaps slightly less efficient in Cd80/86 $-1-$ recipients; Figure $7 \mathbf{B}$ ). Taken together, these data support a model whereby B7/CD28 costimulation 


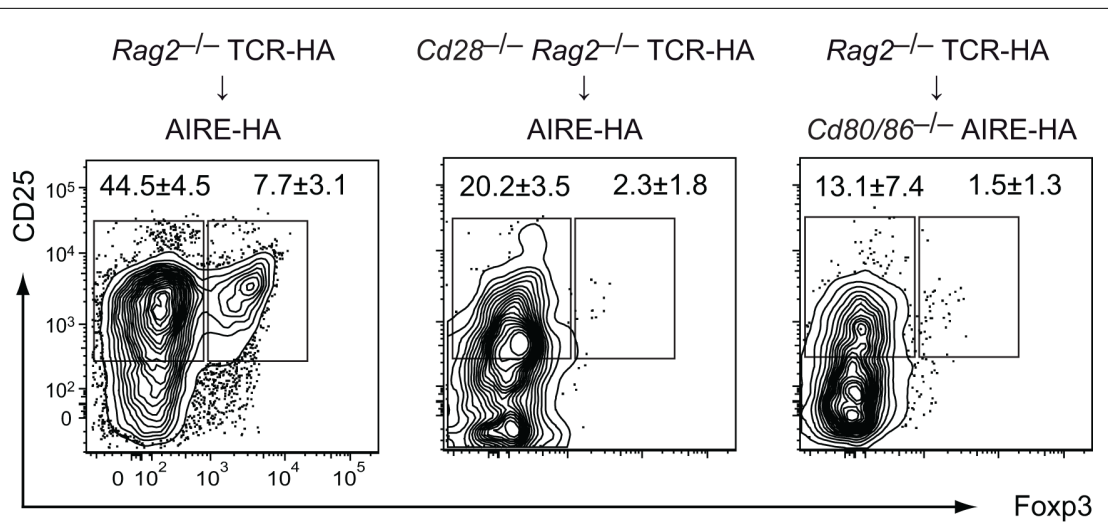

FIGURE 6 | Costimulation is required simultaneous to or in close temporal proximity to the $\mathrm{T}_{\text {reg }}$ lineage-instructing TCR stimulus at the CD4 SP stage. $5 \times 10^{5}$ CD4 SP cells from TCR-HA Foxp3 ${ }^{\text {gip }}$ transgenic animals on a Rag $2^{-1-}$ background (CD45.1) were intrathymically injected into Cd80/86 $6^{+/+}$(left) or Cd80/86 $6^{-/}$AIRE-HA (right) recipients (CD45.2). In a "reciprocal" setting, we injected CD4 SP cells from Cd28-1- TCR-HA Foxp3 $3^{\text {gfp }}$ Rag2 $^{-1-}$ mice into the thymus of costimulation sufficient ( $\mathrm{Cd} 80 / 86^{+/+}$) AIRE-HA recipients (middle). 6 days after transfer, injected cells were analyzed for CD25 and Foxp3 expression. Numbers indicate the average frequency $( \pm S D$ ) of cells within gates ( $n=4$ for all groups). is tightly linked to the TCR-driven first phase of $\mathrm{T}_{\text {reg }}$ differentiation, but is dispensable at the cytokine-dependent second phase.

\section{DISCUSSION}

Our findings suggest that the critical function of B7/CD28 costimulation is to support the development and survival of the $\mathrm{CD}_{25}{ }^{+}$Foxp $3^{-}$intermediate stage of $\mathrm{T}_{\text {reg }}$ differentiation. Furthermore, using adoptive transfer of $\mathrm{T}_{\text {reg }}$ precursors, we could show that costimulation is largely dispensable once the CD25 ${ }^{+}$Foxp $3^{-}$ intermediate stage of $\mathrm{T}_{\text {reg }}$ differentiation has been reached. Hence, the B7 co-stimulus is mainly required simultaneous to or in close temporal proximity to the instructive TCR signal, i.e., at "step one" of $\mathrm{T}_{\text {reg }}$ differentiation. These findings are consistent with two recent reports indicating that there is a substantial diminution of polyclonal $\mathrm{CD}_{2} 5^{+}$Foxp $3^{-} \mathrm{T}_{\text {reg }}$ precursor cells in CD28 deficient mice (Lio et al., 2010; Vang et al., 2010). Importantly, these analyses of polyclonal $\mathrm{T}_{\text {reg }}$ development did not identify the actual fate of "presumptive" $\mathrm{T}_{\text {reg }}$ cells in the absence of B7/CD28 costimulation. Here, the use of a TCR transgenic model of cognate antigen-driven $\mathrm{T}_{\text {reg }}$ differentiation allowed us to reveal that lack of costimulation leads to the physical loss of $\mathrm{T}_{\text {reg }}$ precursors from the $\mathrm{T}$ cell repertoire. As a net effect, it thus appears that CD28 signaling protects $\mathrm{T}_{\text {reg }}$ precursors from clonal deletion and thereby promotes the emergence of a $\mathrm{T}_{\text {reg }}$ repertoire of normal size.

Our findings have obvious implications for the observation that autoimmune prone NOD mice on a CD28 or B7 deficient background develop a more severe and accelerated form of diabetes (Salomon et al., 2000). Thus, it appears that the aggressive form of diabetes in this setting is caused by a deficiency in $T_{\text {reg }}$ cells rather than by escape of otherwise "vetoed" $\mathrm{T}$ cells specificities from central tolerance. Consistent with this, adoptive transfer of polyclonal or islet antigen specific $\mathrm{T}_{\text {reg }}$ cells prevented diabetes in NOD Cd28 $8^{-l-}$ mice (Salomon et al., 2000; Tang et al., 2004).

The avidity model of $\mathrm{T}_{\text {reg }}$ differentiation posits that $\mathrm{T}_{\text {reg }}$ differentiation ensues from cognate antigen interactions whose strength lies in between the signaling intensity required for positive selection on the one hand and clonal deletion on the other hand (Feuerer et al., 2007; Atibalentja et al., 2009; Picca et al., 2009; Simons et al., 2010). We have recently obtained further evidence for this hypothesis by attenuating antigen presentation in the TCR$\mathrm{HA} \times$ AIRE-HA model through "designer micro-RNA" mediated knock-down of MHC class II on mTECs. This resulted in a diminished extent of negative selection and an increased emergence of $\mathrm{T}_{\text {reg }}$ cells, which is consistent with the notion that intermediate avidity-interactions favor $\mathrm{T}_{\text {reg }}$ differentiation over negative selection (Hinterberger et al., 2010). Considering the predictions of the avidity hypothesis, one may have expected TCR-HA ${ }^{+}$cells to escape from negative selection and $\mathrm{T}_{\text {reg }}$ induction and to eventually enter the naïve CD4 T cell pool, if B7/CD28 costimulation merely were to amplify the strength of an integrated signal downstream of the TCR and CD28. However, this is clearly not the case. Instead, lack of costimulation increases the antigen-driven net loss of TCR-HA ${ }^{+}$cells. Hence, our findings indicate that CD28 signaling does not operate primarily through amplifying the TCR signal, but through qualitatively changing the interpretation of the TCR signal and thereby initiating a distinct genetic program. Consistent with this, we found that in the presence of the AIRE-HA transgene, TCR-HA ${ }^{+} \mathrm{CD}_{25}{ }^{-}$Foxp $^{-}$cells displayed identical signs of early activation (up-regulation of PD-1 and GITR and downregulation of the TCR) irrespective of whether they were $\mathrm{Cd} 28^{+/+}$ or $C d 28^{-l-}$. Parallel signals emanating from CD28/B7 costimulation may then support the progression toward the cytokinedependent "step two" of $\mathrm{T}_{\text {reg }}$ differentiation. It remains possible that the early events associated with entry into the $\mathrm{T}_{\text {reg }}$ lineage can even be set off by a TCR signal of matching strength independent of costimulation.

Generally, CD28 co-signals are thought to stabilize mRNAs and amplify the activation of nuclear factor of activated $T$ cells (NFAT) and nuclear factor- $\kappa \mathrm{B}(\mathrm{NF}-\kappa \mathrm{B})$, thereby supporting $\mathrm{T}$ cell cytokine production, proliferation, survival, and differentiation (Rudd et al., 2009). Concerning a potential role of CD28 signaling in cytokine production, it is hard to see how this should 

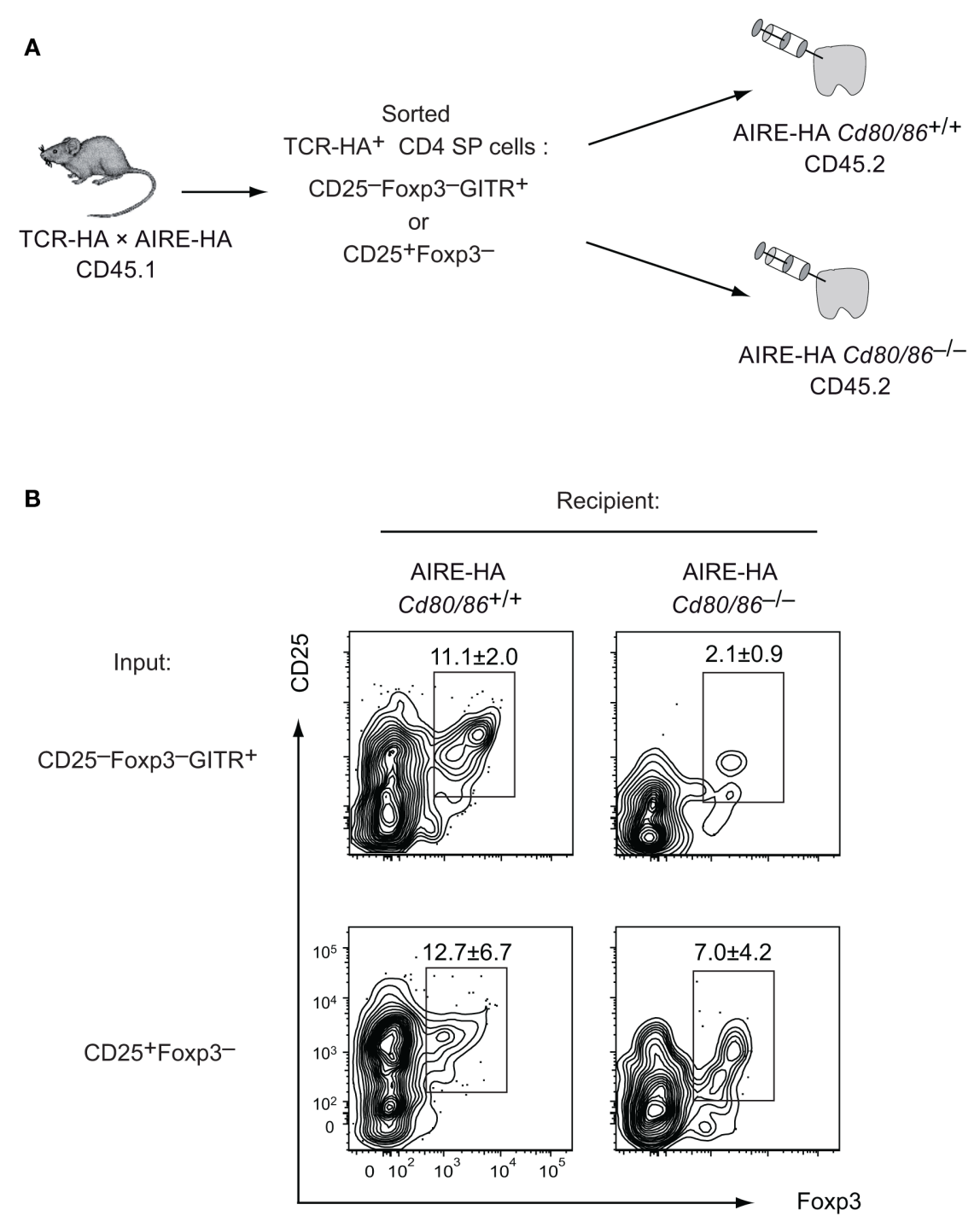

FIGURE 7 |The TCR-driven instructive but not the cytokine-dependent consolidation phase of $T_{\text {reg }}$ differentiation requires costimulation. (A) Experimental design: $\mathrm{TCR}-\mathrm{HA}^{+} \mathrm{T}_{\text {reg }}$ precursor subsets (CD25- Foxp3- GITR $^{+}$and CD25+Foxp3 ${ }^{-}$) were isolated from CD4 SP thymocytes of TCR-HA $\times$ AIRE-HA animals (CD45.1). $4 \times 10^{5}$ cells were i.t. injected into $\mathrm{Cd} 80 / 86^{+/+}$or $\left.\mathrm{Cd} 80\right)^{-/-} \mathrm{AIRE}-\mathrm{HA}$ recipients (CD45.2).
(B) Four days after injection transferred cells were analyzed for CD25 and Foxp3 expression. Numbers indicate the average frequency $( \pm S D$ ) of cells within gates ( $n=3$ for transfer of $\mathrm{CD}^{2} 5^{-}$Foxp3 $^{-}$GITR $^{+}$cells and $n=5$ for transfer of CD25 $5^{+}$Foxp3 $3^{-}$cells; $P=0.0065$ for $\mathrm{CD}^{2} 5^{-}$Foxp3 $^{-} \mathrm{GITR}^{+}$input cells and $P=0.15$ for CD25+Foxp3-input cells). account for the block of thymic $\mathrm{T}_{\text {reg }}$ development at "step one," which is believed to be TCR-driven but cytokine independent. Along these lines, we and others found that the bottleneck in $\mathrm{T}_{\text {reg }}$ development caused by CD28 deficiency affects a stage of $\mathrm{T}_{\text {reg }}$ differentiation considerably upstream of the perturbations that are caused by IL-2 deficiency (Bayer et al., 2005; D'Cruz and Klein, 2005; Fontenot et al., 2005a; Setoguchi et al., 2005; Vang et al., 2008). As already discussed above, it also appears highly unlikely that CD28 functions to merely amplify the TCR signal. Sequence analyzes of polyclonal $\mathrm{T}_{\text {reg }}$ cells generated in the absence or presence of costimulation also argue against this scenario (Lio et al., 2010). Thus, it was found that the residual $\mathrm{T}_{\text {reg }}$ cell repertoire generated in the absence of CD28 was not dramatically altered at the level of TCR specificities. Instead, the relative abundance of individual TCR specificities within the contracted $\mathrm{T}_{\text {reg }}$ pool of $C d 28^{-1-}$ mice resembled that of the $\mathrm{WT} \mathrm{T}_{\text {reg }}$ repertoire, at least with regard to abundant specificities (Lio et al., 2010). On this basis, it was suggested that CD28 signaling provides signals (parallel to TCR stimulation) that facilitate $\mathrm{T}_{\text {reg }}$ development, but by themselves are not truly essential (Lio et al., 2010).

An alternative explanation why the polyclonal $\mathrm{T}_{\text {reg }}$ compartment is reduced by about $80 \%$ in $C d 28^{-1-}$ mice would be that some, but not other TCRs depend upon CD28 co-signals to segregate into the $\mathrm{T}_{\text {reg }}$ compartment. However, our observations in a TCR transgenic system are more consistent with the "facilitator" scenario, as the differentiation of quasi-monoclonal TCR-HA ${ }^{+}$ 
$\mathrm{T}_{\text {reg }}$ cells is diminished by a factor of about five-fold rather than being fully abolished (or not being affected at all).

In order to explain why the defect in CD28 or B7 deficient mice is quantitative rather than qualitative, we considered the hypothesis that costimulation might foster $\mathrm{T}_{\text {reg }}$ generation through promoting the proliferative expansion of $\mathrm{T}_{\text {reg }}$ precursors rather than actually instructing their differentiation per se. However, we could not find any evidence that this was the case. In fact, the proliferation of $\mathrm{T}_{\text {reg }}$ precursors was even increased in the absence of costimulation, perhaps suggesting a compensatory mechanism. On the basis of this finding, the most plausible scenario is that CD28 signaling serves a dual, partly instructive (as bona fide differentiation factor) and partly permissive (as survival factor) function during $\mathrm{T}_{\text {reg }}$ differentiation. Of note, neither function appears to be truly essential, so that the role of costimulation is indeed perhaps better described as that of a "catalyst."

The full spectrum of molecular events downstream of CD28 signaling during $\mathrm{T}_{\text {reg }}$ differentiation remains to be established. However, recent work has shed light on how costimulation may support the differentiation of $\mathrm{T}_{\text {reg }}$ precursors through qualitatively modulating signaling events downstream of the TCR. CD28 communicates with several downstream signaling cascades through distinct motifs in its cytoplasmic tail that mediate interactions with Lck and the PI3K pathway, respectively. Several groups have reported that efficient $T_{\text {reg }}$ cell generation does not require CD28's PI3K-binding motif, whereas the Lck-interacting $\mathrm{P}_{187}$ YAPP motif seems to be crucial for $\mathrm{T}_{\text {reg }}$ differentiation (Tai et al., 2005; Lio et al., 2010; Vang et al., 2010). Mutations in the CD28 $\mathrm{P}_{187}$ YAPP motif strongly diminish TCR/CD28 mediated NF- $\kappa \mathrm{B}$ activation (Sanchez-Lockhart et al., 2008), and the ablation of genes involved in NF-кB activation (PKC- $\theta$, CARMA-1, Bcl-10, IKK-2) impairs thymic $\mathrm{T}_{\text {reg }}$ differentiation (Schmidt-Supprian et al., 2004; Barnes et al., 2009; Medoff et al., 2009). The recent identification of c-Rel as essential NF- $\kappa$ B family transcription factor in $\mathrm{T}_{\text {reg }}$ differentiation may provide important clues as to how integrated TCR/CD28 signaling activates the transcriptional program that controls $\mathrm{T}_{\text {reg }}$ differentiation (Isomura et al., 2009; Long et al., 2009; Ruan et al., 2009; Deenick et al., 2010; Visekruna et al.,

\section{REFERENCES}

Apostolou, I., Sarukhan, A., Klein, L., and von Boehmer, H. (2002). Origin of regulatory $\mathrm{T}$ cells with known specificity for antigen. Nat. Immunol. 3, 756-763.

Aschenbrenner, K., D'Cruz, L. M., Vollmann, E. H., Hinterberger, M., Emmerich, J., Swee, L. K., Rolink, A., and Klein, L. (2007). Selection of Foxp3+ regulatory $\mathrm{T}$ cells specific for self antigen expressed and presented by Aire+ medullary thymic epithelial cells. Nat. Immunol. 8, 351-358.

Atibalentja, D. F., Byersdorfer, C. A., and Unanue, E. R. (2009). Thymusblood protein interactions are highly effective in negative selection and regulatory $\mathrm{T}$ cell induction. $J$. Immunol. 183, 7909-7918.
Barnes, M. J., Krebs, P., Harris, N., Eidenschenk, C., Gonzalez-Quintial, R., Arnold, C. N., Crozat, K., Sovath, S., Moresco, E. M., Theofilopoulos, A. N., Beutler, B., and Hoebe, K. (2009). Commitment to the regulatory $\mathrm{T}$ cell lineage requires CARMA1 in the thymus but not in the periphery. PLOS Biol. 7, e51. doi: 10.1371/journal.pbio.1000051

Bayer, A. L., Lee, J. Y., de la Barrera, A., Surh, C. D., and Malek, T. R. (2008). A function for IL7R for CD4+CD25+Foxp3+ T regulatory cells. J. Immunol. 181, 225-234.

Bayer, A. L., Yu, A., Adeegbe, D., and Malek, T. R. (2005). Essential role for interleukin-2 for CD4(+)CD25(+) T regulatory cell development during

2010). One aspect of c-Rel's function seems to be direct control of the Foxp3 gene through binding to a DNA motif resembling the CD28-response element in the IL-2 gene (Zheng et al., 2010). It has been suggested that through opening and remodeling of the Foxp3 locus, c-Rel activation downstream of TCR/CD28 signaling may serve a bona fide lineage instructing function (Josefowicz and Rudensky, 2009). However, considering that $\mathrm{T}_{\text {reg }}$ differentiation can proceed surprisingly well in the absence of a functional Foxp3 gene (Gavin et al., 2007; Hill et al., 2007; Lin et al., 2007; Lahl et al., 2009), it appears reasonable to assume that NF-кBsignaling or other signaling pathways downstream of CD28 also initiate further - as yet unknown - instructive molecular events not related to Foxp3-induction. At the same time, it is likely that CD28 signaling in parallel elicits a transcriptional program that is of rather permissive nature. It may thereby set the stage for "step two" of intrathymic $\mathrm{T}_{\text {reg }}$ differentiation, for instance by up-regulating components of the IL-2 receptor (Lio et al., 2010; Vang et al., 2010). Unraveling these functions will be challenging, since the presumed lineage instructing function of IL-2 signaling in $\mathrm{T}_{\text {reg }}$ cells is, on the one hand, not absolute and, on the other hand, inextricably intertwined with its pro-survival function (Malek et al., 2002; D'Cruz and Klein, 2005; Fontenot et al., 2005a). Furthermore, it also remains to be established in how far CD28 costimulation may directly influence the survival of $\mathrm{T}_{\text {reg }}$ precursors through controlling pro-survival genes such as Bcl$\mathrm{x}_{\mathrm{L}}$, akin to its function in mature, "conventional" $\mathrm{T}$ cells (Boise et al., 1995; Shi et al., 1995; Noel et al., 1996; Radvanyi et al., 1996). However, given the evidence that the PI3-kinase pathway is important for induction of Bcl- $\mathrm{x}_{\mathrm{L}}$ by CD28 (Burr et al., 2001; Okkenhaug et al., 2001), yet that the PI3K interacting motif in CD28 is dispensable for efficient $\mathrm{T}_{\text {reg }}$ induction (Tai et al., 2005; Lio et al., 2010; Vang et al., 2010), this scenario appears less likely.

\section{ACKNOWLEDGMENTS}

This work was supported by grants from the Deutsche Forschungsgemeinschaft (KL 1228/3-1 to Ludger Klein and Maria Hinterberger; SFB 571 to Ludger Klein and Gerald Wirnsberger).

the neonatal period. J. Exp. Med. 201, 769-777.

Boise, L. H., Minn, A. J., Noel, P. J., June, C. H., Accavitti, M. A., Lindsten, T. and Thompson, C. B. (1995). CD28 costimulation can promote $\mathrm{T}$ cell survival by enhancing the expression of Bcl-XL. Immunity 3, 87-98.

Borriello, F., Sethna, M. P., Boyd, S. D., Schweitzer, A. N., Tivol, E. A., Jacoby, D., Strom, T. B., Simpson, E. M., Freeman, G. J., and Sharpe, A. H. (1997). B7-1 and B7-2 have overlapping, critical roles in immunoglobulin class switching and germinal center formation. Immunity 6, 303-313.

Bour-Jordan, H., Esensten, J. H., Martinez-Llordella, M., Penaranda, C., Stumpf, M., and Bluestone, J. A.
(2011). Intrinsic and extrinsic control of peripheral T-cell tolerance by costimulatory molecules of the CD28/B7 family. Immunol. Rev. 241, 180-205.

Burchill, M. A., Yang, J., Vang, K. B. Moon, J. J., Chu, H. H., Lio, C. W., Vegoe, A. L., Hsieh, C. S., Jenkins, M. K., and Farrar, M. A. (2008). Linked T cell receptor and cytokine signaling govern the development of the regulatory $\mathrm{T}$ cell repertoire. Immunity 28, 112-121.

Burr, J. S., Savage, N. D., Messah, G. E., Kimzey, S. L., Shaw, A. S., Arch, R. H., and Green, J. M. (2001). Cutting edge: distinct motifs within CD28 regulate $\mathrm{T}$ cell proliferation and induction of Bcl-XL. J. Immunol. $166,5331-5335$. 
D’Cruz, L. M., and Klein, L. (2005). Development and function of agonist-induced CD25+Foxp3+ regulatory $\mathrm{T}$ cells in the absence of interleukin 2 signaling. Nat. Immunol. 6, 1152-1159.

Deenick, E. K., Elford, A. R., Pellegrini, M., Hall, H., Mak, T. W., and Ohashi, P. S. (2010). c-Rel but not NF-kappaB1 is important for T regulatory cell development. Eur. J. Immunol. 40, 677-681.

Feuerer, M., Jiang, W., Holler, P. D., Satpathy, A., Campbell, C., Bogue, M., Mathis, D., and Benoist, C. (2007). Enhanced thymic selection of FoxP3+ regulatory $\mathrm{T}$ cells in the NOD mouse model of autoimmune diabetes. Proc. Natl. Acad. Sci. U.S.A. 104, 18181-18186.

Fontenot, J. D., Rasmussen, J. P., Gavin, M. A., and Rudensky, A. Y. (2005a). A function for interleukin 2 in Foxp3expressing regulatory $\mathrm{T}$ cells. Nat. Immunol. 6, 1142-1151.

Fontenot, J. D., Rasmussen, J. P., Williams, L. M., Dooley, J. L., Farr, A. G., and Rudensky, A. Y. (2005b). Regulatory $\mathrm{T}$ cell lineage specification by the forkhead transcription factor foxp3. Immunity 22, 329-341.

Fraser, J. D., Irving, B. A., Crabtree, G. R., and Weiss, A. (1991). Regulation of interleukin-2 gene enhancer activity by the $\mathrm{T}$ cell accessory molecule CD28. Science 251, 313-316.

Gavin, M. A., Rasmussen, J. P., Fontenot, J. D., Vasta, V., Manganiello, V. C., Beavo, J. A., and Rudensky, A. Y. (2007). Foxp3-dependent programme of regulatory T-cell differentiation. Nature 445, 771-775.

Hill, J. A., Feuerer, M., Tash, K., Haxhinasto, S., Perez, J., Melamed, R., Mathis, D., and Benoist, C. (2007). Foxp3 transcription-factordependent and -independent regulation of the regulatory $\mathrm{T}$ cell transcriptional signature. Immunity 27, 786-800.

Hinterberger, M., Aichinger, M., da Costa, O. P., Voehringer, D., Hoffmann, R., and Klein, L. (2010). Autonomous role of medullary thymic epithelial cells in central CD4(+) $\mathrm{T}$ cell tolerance. Nat. Immunol. 11, 512-519.

Hsieh, C. S., Zheng, Y., Liang, Y., Fontenot, J. D., and Rudensky, A. Y. (2006). An intersection between the self-reactive regulatory and nonregulatory $\mathrm{T}$ cell receptor repertoires. Nat. Immunol. 7, 401-410.

Isomura, I., Palmer, S., Grumont, R. J., Bunting, K., Hoyne, G., Wilkinson, N., Banerjee, A., Proietto, A., Gugasyan, R., Wu, L., McNally, A.,
Steptoe, R. J., Thomas, R., Shannon, M. F., and Gerondakis, S. (2009). cRel is required for the development of thymic Foxp3+ CD4 regulatory $\mathrm{T}$ cells. J. Exp. Med. 206, 3001-3014.

Jenkins, M. K., Taylor, P. S., Norton, S. D., and Urdahl, K. B. (1991). CD28 delivers a costimulatory signal involved in antigen-specific IL2 production by human T cells. $J$. Immunol. 147, 2461-2466.

Jordan, M. S., Boesteanu, A., Reed, A. J., Petrone, A. L., Holenbeck, A. E., Lerman, M. A., Naji, A., and Caton, A. J. (2001). Thymic selection of $\mathrm{CD} 4+\mathrm{CD} 25+$ regulatory $\mathrm{T}$ cells induced by an agonist self-peptide. Nat. Immunol. 2, 301-306.

Josefowicz, S. Z., and Rudensky, A. (2009). Control of regulatory $\mathrm{T}$ cell lineage commitment and maintenance. Immunity 30, 616-625.

Kawahata, K., Misaki, Y., Yamauchi, M., Tsunekawa, S., Setoguchi, K., Miyazaki, J., and Yamamoto, K. (2002). Generation of CD4(+)CD25(+) regulatory $\mathrm{T}$ cells from autoreactive $\mathrm{T}$ cells simultaneously with their negative selection in the thymus and from nonautoreactive $\mathrm{T}$ cells by endogenous TCR expression. J. Immunol. 168, 4399-4405.

Kirberg, J., Baron, A., Jakob, S., Rolink, A., Karjalainen, K., and von Boehmer, H. (1994). Thymic selection of CD8+ single positive cells with a class II major histocompatibility complex-restricted receptor. $J$. Exp. Med. 180, 25-34.

Lahl, K., Mayer, C. T., Bopp, T., Huehn, J., Loddenkemper, C., Eberl, G., Wirnsberger, G., Dornmair, K., Geffers, R., Schmitt, E., Buer, J., and Sparwasser, T. (2009). Nonfunctional regulatory $\mathrm{T}$ cells and defective control of Th2 cytokine production in natural scurfy mutant mice. J. Immunol. 183, 5662-5672.

Lin, W., Haribhai, D., Relland, L. M., Truong, N., Carlson, M. R., Williams, C. B., and Chatila, T. A. (2007). Regulatory $\mathrm{T}$ cell development in the absence of functional Foxp3. Nat. Immunol. 8, 359-368.

Lindstein, T., June, C. H., Ledbetter, J. A., Stella, G., and Thompson, C. B. (1989). Regulation of lymphokine messenger RNA stability by a surface-mediated $\mathrm{T}$ cell activation pathway. Science 244, 339-343.

Lio, C. W., Dodson, L. F., Deppong, C. M., Hsieh, C. S., and Green, J. M. (2010). CD28 facilitates the generation of Foxp3- cytokine responsive regulatory $\mathrm{T}$ cell precursors. $J$. Immunol. 184, 6007-6013.
Lio, C. W., and Hsieh, C. S. (2008). A two-step process for thymic regulatory $\mathrm{T}$ cell development. Immunity 28, 100-111.

Lio, C. W., and Hsieh, C. S. (2011) Becoming self-aware: the thymic education of regulatory T cells. Curr. Opin. Immunol. 23, 213-219.

Lohr, J., Knoechel, B., Kahn, E. C., and Abbas, A. K. (2004). Role of B7 in $\mathrm{T}$ cell tolerance. J. Immunol. 173, 5028-5035.

Long, M., Park, S. G., Strickland, I., Hayden, M. S., and Ghosh, S. (2009). Nuclear factor-kappaB modulates regulatory $\mathrm{T}$ cell development by directly regulating expression of Foxp 3 transcription factor. Immunity 31, 921-931.

Malek, T. R., Yu, A., Vincek, V., Scibelli, P., and Kong, L. (2002). CD4 regulatory $\mathrm{T}$ cells prevent lethal autoimmunity in IL-2Rbeta-deficient mice. Implications for the nonredundant function of IL-2. Immunity 17, 167-178.

Mayack, S. R., and Berg, L. J. (2006). Cutting edge: an alternative pathway of CD4+ T cell differentiation is induced following activation in the absence of gamma-chain-dependent cytokine signals. J. Immunol. 176 2059-2063.

Medoff, B. D., Sandall, B. P., Landry, A., Nagahama, K., Mizoguchi, A., Luster, A. D., and Xavier, R. J. (2009). Differential requirement for CARMA1 in agonist-selected T-cell development. Eur. J. Immunol. 39, 78-84.

Noel, P. J., Boise, L. H., Green, J. M., and Thompson, C. B. (1996). CD28 costimulation prevents cell death during primary $\mathrm{T}$ cell activation. $J$. Immunol. 157, 636-642.

Okkenhaug, K., Wu, L., Garza, K. M., La Rose, J., Khoo, W., Odermatt, B., Mak, T. W., Ohashi, P. S., and Rottapel, R. (2001). A point mutation in CD28 distinguishes proliferative signals from survival signals. Nat. Immunol. 2, 325-332.

Pacholczyk, R., Ignatowicz, H., Kraj, P., and Ignatowicz, L. (2006). Origin and $\mathrm{T}$ cell receptor diversity of Foxp3+CD4+CD25+ T cells. Immunity 25, 249-259.

Papiernik, M., de Moraes, M. L., Pontoux, C., Vasseur, F., and Penit, C. (1998). Regulatory CD4 T cells: expression of IL-2R alpha chain, resistance to clonal deletion and IL-2 dependency. Int. Immunol. 10, 371-378.

Picca, C. C., Oh, S., Panarey, L. Aitken, M., Basehoar, A., and Caton, A. J. (2009). Thymocyte deletion can bias Treg formation toward low-abundance selfpeptide. Eur. J. Immunol. 39, 3301-3306.

Radvanyi, L. G., Shi, Y., Vaziri, H., Sharma, A., Dhala, R., Mills, G. B., and Miller, R. G. (1996). CD28 costimulation inhibits TCRinduced apoptosis during a primary $\mathrm{T}$ cell response. J. Immunol. 156, 1788-1798.

Ribot, J., Romagnoli, P., and van Meerwijk, J. P. (2006). Agonist ligands expressed by thymic epithelium enhance positive selection of regulatory $\mathrm{T}$ lymphocytes from precursors with a normally diverse TCR repertoire. J. Immunol. 177, 1101-1107.

Ruan, Q., Kameswaran, V., Tone, Y., Li, L., Liou, H. C., Greene, M. I., Tone, M., and Chen, Y. H. (2009) Development of Foxp3(+) regulatory $\mathrm{T}$ cells is driven by the cRel enhanceosome. Immunity 31, 932-940.

Rudd, C. E., Taylor, A., and Schneider, H. (2009). CD28 and CTLA-4 coreceptor expression and signal transduction. Immunol. Rev. 229, 12-26.

Sakaguchi, S. (2004). Naturally arising CD4+ regulatory $\mathrm{T}$ cells for immunologic self-tolerance and negative control of immune responses. Annu. Rev. Immunol. 22, 531-562.

Salomon, B., Lenschow, D. J., Rhee, L., Ashourian, N., Singh, B., Sharpe, A., and Bluestone, J. A. (2000). B7/CD28 costimulation is essential for the homeostasis of the CD4+CD25+ immunoregulatory $\mathrm{T}$ cells that control autoimmune diabetes. Immunity 12, 431-440.

Sanchez-Lockhart, M., Graf, B., and Miller, J. (2008). Signals and sequences that control CD28 localization to the central region of the immunological synapse. J. immunol. 181, 7639-7648.

Schmidt-Supprian, M., Tian, J., Grant, E. P., Pasparakis, M., Maehr, R., Ovaa, H., Ploegh, H. L., Coyle, A. J., and Rajewsky, K. (2004). Differential dependence of CD4+CD25+ regulatory and natural killer-like $\mathrm{T}$ cells on signals leading to NF-kappaB activation. Proc. Natl. Acad. Sci. U.S.A. 101, 4566-4571.

Setoguchi, R., Hori, S., Takahashi, T. and Sakaguchi, S. (2005). Homeostatic maintenance of natural Foxp3(+) CD25(+) CD4(+) regulatory $\mathrm{T}$ cells by interleukin (IL) -2 and induction of autoimmune disease by IL-2 neutralization. J. Exp. Med. 201, 723-735. 
Shahinian, A., Pfeffer, K., Lee, K. P., Kundig, T. M., Kishihara, K., Wakeham, A., Kawai, K., Ohashi, P. S., Thompson, C. B., and Mak, T. W. (1993). Differential T cell costimulatory requirements in CD28-deficient mice. Science 261, 609-612.

Shi, Y., Radvanyi, L. G., Sharma, A., Shaw, P., Green, D. R., Miller, R. G., and Mills, G. B. (1995). CD28-mediated signaling in vivo prevents activation-induced apoptosis in the thymus and alters peripheral lymphocyte homeostasis. J. Immunol. 155, 1829-1837.

Simons, D. M., Picca, C. C., Oh, S., Perng, O. A., Aitken, M., Erikson, J., and Caton, A. J. (2010). How specificity for self-peptides shapes the development and function of regulatory T cells. J. Leukoc. Biol. 88, 1099-1107.

Tai, X., Cowan, M., Feigenbaum, L., and Singer, A. (2005). CD28 costimulation of developing thymocytes induces Foxp3 expression and regulatory $\mathrm{T}$ cell differentiation independently of interleukin 2. Nat. Immunol. 6, 152-162.
Tang, Q., Henriksen, K. J., Bi, M., Finger, E. B., Szot, G., Ye, J., Masteller, E. L., McDevitt, H., Bonyhadi, M., and Bluestone, J. A. (2004). In vitro-expanded antigen-specific regulatory $\mathrm{T}$ cells suppress autoimmune diabetes. J. Exp. Med. 199, 1455-1465.

Tang, Q., Henriksen, K. J., Boden, E. K., Tooley, A. J., Ye, J., Subudhi, S. K., Zheng, X. X., Strom, T. B., and Bluestone, J. A. (2003). Cutting edge: $\mathrm{CD} 28$ controls peripheral homeostasis of $\mathrm{CD} 4+\mathrm{CD} 25+$ regulatory $\mathrm{T}$ cells. J. Immunol. 171, 3348-3352.

Vang, K. B., Yang, J., Mahmud, S. A., Burchill, M. A., Vegoe, A. L., and Farrar, M. A. (2008). IL-2, 7 , and -15 , but not thymic stromal lymphopoeitin, redundantly govern CD4+Foxp3+ regulatory $\mathrm{T}$ cell development. J. Immunol. 181, 3285-3290.

Vang, K. B., Yang, J., Pagan, A. J., Li, L. X., Wang, J., Green, J. M., Beg, A. A., and Farrar, M. A. (2010). Cutting edge: CD28 and c-Rel-dependent pathways initiate regulatory $\mathrm{T}$ cell development. J. Immunol. 184, 4074-4077.
Visekruna, A., Huber, M., Hellhund, A., Bothur, E., Reinhard, K., Bollig, N., Schmidt, N., Joeris, T., Lohoff, M., and Steinhoff, U. (2010). cRel is crucial for the induction of Foxp3(+) regulatory CD4(+) T cells but not $\mathrm{T}(\mathrm{H}) 17$ cells. Eur. J. Immunol. 40, 671-676.

Wirnsberger, G., Hinterberger, M., and Klein, L. (2011). Regulatory T-cell differentiation versus clonal deletion of autoreactive thymocytes. Immunol. Cell Biol. 89, 45-53.

Wirnsberger, G., Mair, F., and Klein, L. (2009). Regulatory T cell differentiation of thymocytes does not require a dedicated antigen-presenting cell but is under T cell-intrinsic developmental control. Proc. Natl. Acad. Sci. U.S.A. 106, 10278-10283.

Yao, Z., Kanno, Y., Kerenyi, M., Stephens, G., Durant, L., Watford, W. T., Laurence, A., Robinson, G. W., Shevach, E. M., Moriggl, R., Hennighausen, L., Wu, C., and O'Shea, J. J. (2007). Nonredundant roles for Stat $5 \mathrm{a} / \mathrm{b}$ in directly regulating Foxp3. Blood 109, 4368-4375.

Zheng, Y., Josefowicz, S., Chaudhry, A., Peng, X. P., Forbush, K., and Rudensky, A. Y. (2010). Role of conserved non-coding DNA elements in the
Foxp3 gene in regulatory T-cell fate. Nature 463, 808-812.

Conflict of Interest Statement: The authors declare that the research was conducted in the absence of any commercial or financial relationships that could be construed as a potential conflict of interest.

Received: 15 June 2011; paper pending published: 07 July 2011; accepted: 14 July 2011; published online: 25 July 2011.

Citation: Hinterberger M, Wirnsberger $G$ and Klein L (2011) B7/CD28 in central tolerance: costimulation promotes maturation of regulatory $T$ cell precursors and prevents their clonal deletion. Front. Immun. 2:30. doi: 10.3389/fimmu.2011.00030

This article was submitted to Frontiers in Immunological Tolerance, a specialty of Frontiers in Immunology.

Copyright (๑) 2011 Hinterberger, Wirnsberger and Klein. This is an open-access article subject to a non-exclusive license between the authors and Frontiers Media $S A$, which permits use, distribution and reproduction in other forums, provided the original authors and source are credited and other Frontiers conditions are complied with. 